\title{
Cold Tolerance in Two Large Maize Inbred Panels Adapted to European Climates
}

$\mathrm{M}$ aize (Zea mays L.), one of the three major crops in the world, was domesticated in the tropical highlands of America and is currently grown in cooler areas all over the world. Such wide adaptation is mainly due to selection for cold tolerance. However, the genetic variation for cold tolerance in maize is limited, and sources of cold tolerance frequently have low agronomic performance compared with commercial standards. Consequently, classical maize breeding for the complex trait cold tolerance has reached a plateau, and the new molecular tools have not solved this handicap so far. Moreover, cold tolerance evaluations have large experimental errors and genotype by environment interaction. Besides, field trials often suffer unpredictable weather conditions for scoring cold tolerance, whereas trials under controlled conditions are not very well correlated with field performance.

Improving cold tolerance is an important task that could be challenged by enlarging the breeding base, optimizing the evaluation methods, and designing more efficient breeding programs. Sources of cold tolerance among the elite germplasm need to be identified, new evaluation methods and selection criteria need to be investigated, and the relationships between traits recorded in diverse environments need to be studied.
In the September-October 2014 issue of Crop Science, researchers evaluated two panels of dent and flint maize inbred lines adapted to European conditions per se and in test crosses, both in the field and under favorable and cold conditions in a growth chamber to investigate the effects of cold tolerance-related traits on biomass production. The genotypic data, diversity, and relationship matrices of Rincent et al. (2012) were used for defining genetic relationships among inbred lines. Phenotyping included agronomic and physiological traits. Analyses of variance, regressions and correlations were calculated, and the genetic structure was included in the model for comparison of groups of genotypes.

Environments and the genotype by environment interactions significantly affected cold tolerance, and for individual environments, differences were significant among inbreds and among hybrids. Under cold conditions in a growth chamber, dent inbreds per se germinated earlier and had a higher early vigor although less chlorophyll and lower efficiency of photosystem II than flint inbreds. When comparing cold to favorable conditions in the growth chamber, flints had a larger increase in days to emergence and smaller reductions in chlorophyll content and efficiency of photosystem II than dents while the decrease in early vigor was similar between dents and flints. The European flints are believed to be more tolerant to cold conditions because they are more adapted to northern latitudes than the Corn Belt dents; however, the origin of a variety in a cold region does not warrant cold tolerance. One dent and eight flint inbreds with diverse origins were the most cold tolerant inbreds. The most cold tolerant dent and flint groups were related to the Iodent Ph207 and the Northern Flint D171, respectively.

The correlations between traits determined in inbreds per se and in test crosses and between traits from controlled and field conditions were low. Regressions with dry matter yield in the field as the dependent variable identified plant height $\left(R^{2}=0.285\right)$ as the main independent variable, followed by quantum efficiency of photosystem II. Cold tolerance had low and negative effects on 
dry matter yield. Models based on traits scored in early developmental stages are not expected to accurately predict biomass production under cold conditions. Crosses between flint inbreds from some Northern Flint groups and some dent inbreds could be potential sources of base germplasm for improving cold tolerance.

\section{Reference}

Rincent, R., D. Laloë, S. Nicolas, T. Altmann, D. Brunel, P. Revilla et al. 2012. Maximizing the reliability of genomic selection by optimizing the calibration set of reference individuals: comparison of methods in two diverse groups of maize inbreds (Zea mays L.). Genetics 192:715-728.

Adapted from Revilla, P., V.M. Rodríguez, A. Ordás, R. Rincent, A. Charcosset, C. Giauffret et al. 2014. Cold tolerance in two large maize inbred panels adapted to European climates. Crop Sci. 54:1981-1991. View the complete article online at www.crops.org/publications/ cs/articles/54/5/1981 (journal subscribers) or https:// dl.sciencesocieties.org/publications/cs/articles/54/5/1981 (Digital Library)

doi:10.2134/csa2014-59-11-11
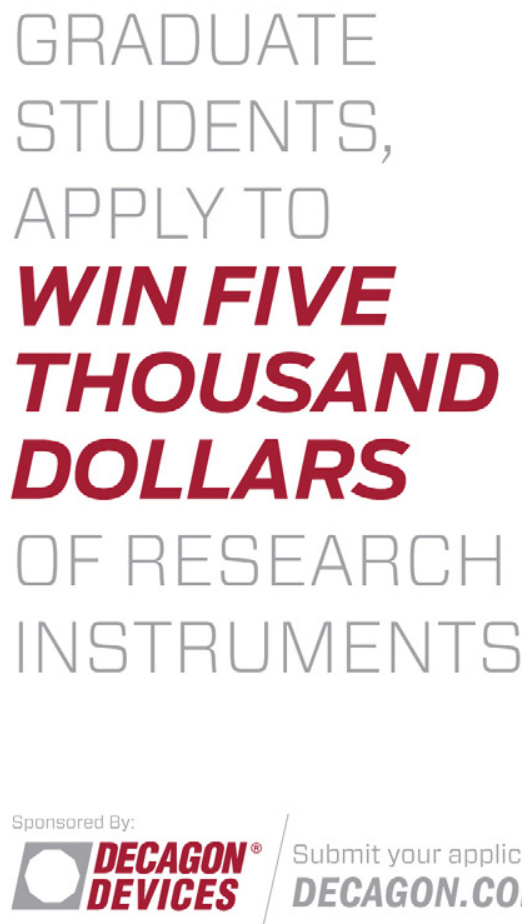
DECAGON.COM/GAHARRIS
Pore-Water Extraction from Unsaturated
Porous Media

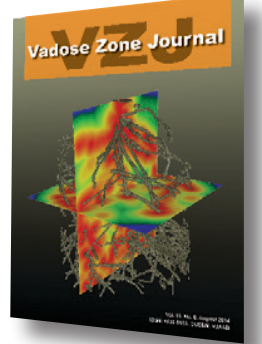

C ontamination of the vadose zone is a particularly difficult problem to remedy; water moves relatively slowly compared with saturated material. This problem can be localized or grow to a much larger scale when soluble contaminants migrate down to the groundwater table. This will then result in contamination of the aquifer over a much larger spatial scale and persist for a long time into the future. Removal of water from the vadose zone is complicated as the water is held by strong capillary forces specifically in lowpermeability sediments.

At the Hanford Site in Washington State, past activities have led to presence of technetium-99 in low-permeability sediments at high water content. Scientists have for years sought to slow the downward migration of this contaminated water. In a recent issue of Vadose Zone Journal, researchers suggest an innovative method: sustained extraction of contaminated pore water from the low-permeability layers in the vadose zone. If successful at the field scale, this could prevent further migration to the subsurface. The authors devised a series of laboratory experiments using repacked Hanford sediments, as well as numerical experiments for pore-water extraction from the vadose zone. The pore water was then extracted using a vacuum pump and simulated using a numerical model.

The results showed that, perhaps surprisingly, presence of high-permeability layers impeded water flow because the material dried too quickly. The wetter, low-permeability layers promoted flow for longer periods of time, increasing water extraction. The predicted capillary pressure using the numerical model (with the proper initial and boundary conditions) matched the measured values from the laboratory experiments. These results offer a glimpse of the saturation gradients as a result of the extraction process, something that could potentially be designed into large-scale remedial systems.

The success of this research offers hope that this method can be used in actual field settings to reduce contamination of groundwater.

Adapted from Oostrom, M., M.J. Truex, T.W. Wietsma, and G.D. Tartakovsky. 2014. Pore-water extraction from unsaturated porous media: intermediate-scale laboratory experiments and simulations. Vadose Zone J. 13(8). View the complete article online at https:// www.soils.org/publications/vzj/articles/13/8/vzj2014.04.0044 (journal subscribers) or https://dl.sciencesocieties.org/ publications/vzj/articles/13/8/vzj2014.04.0044 (Digital Library)

doi:10.2134/csa2014-59-11-12 